\title{
Sexual harassment against female nurses: a systematic review
}

\author{
Woldegebriel Gebregziabher Kahsay ${ }^{1,2}$, Reza Negarandeh ${ }^{3^{*}}$ (D), Nahid Dehghan Nayeri ${ }^{4}$ and Marzieh Hasanpour ${ }^{5}$
}

\begin{abstract}
Background: Sexual harassment is complex and has occupational hazards in nursing. Nurses experienced it than other employees. Female nurses are with the highest rate in the profession. Our aim was to determine the prevalence of sexual harassment against female nurses, the types, perpetrators, and health consequences of the harassment.

Method: We undertook a systematic review to synthesize quantitative research studies found in Pubmed, Scopus, ProQuest, Web of Science and Google Scholar databases. The studies included were observational, on sexual harassment against female nurse, full text, and published in peer-reviewed English journals up to August 2018. Two independent reviewers searched the articles and extracted data from the articles. The quality of the articles was evaluated using the Modified Newcastle Ottawa Scale for Cross-Sectional Studies Quality Assessment Tool. A descriptive analysis was done to determine the rate of items from the percentages or proportions of the studies.

Result: The prevalence of sexual harassment against female nurses was $43.15 \%$. It ranged 10 to $87.30 \%$. The $35 \%$ of the female nurses were verbally, $32.6 \%$ non-verbally, $31 \%$ physically and $40.8 \%$ were being harassed psychologically. The $46.59 \%$ of them were harassed by patients, $41.10 \%$ by physicians, $27.74 \%$ by patients' family, $20 \%$ by nurses and $17.8 \%$ were by other coworker perpetrators. The $44.6 \%$ of them were developed mental problems, $30.19 \%$ physical health problems, $61.26 \%$ emotional, $51.79 \%$ had psychological disturbance and $16.02 \%$ with social health problems.

Conclusion: The prevalence of sexual harassment against female nurses is high. Female nurses are being sexually harassed by patients, patient families, physicians, nurses, and other coworkers. The harassment is affecting mental, physical, emotional, social and psychological health of female nurses. It is recommended policymakers to develop guidelines on work ethics, legality and counseling programs. Nursing associations to initiate development of workplace safety policy. A safe and secure working environment is needed in the nursing practice and nursing curriculum in prevention strategy. Research is needed on factors associated with sexual harassment. Since only female nurses were the participants, it could not be representative of all nurses. There was no fund of this review.
\end{abstract}

Keywords: Female nurses, Health consequences, Perpetrators, Prevalence, Sexual harassment

\section{Background}

Sexual harassment and violence against nurses is complex and also became occupational hazards in the nursing profession. This happened to the opposite of the professional mission to care who appears to be at the highest risk of

\footnotetext{
* Correspondence: rnegarandeh@tums.ac.ir; negarandeh@gmail.com ${ }^{3}$ Nursing and Midwifery Care Research Center, School of Nursing and Midwifery, Tehran University of Medical Sciences, Nosrat St., Tohid Sq.. Tehran Postal code: 1419733171, Iran

Full list of author information is available at the end of the article
}

workplace violence [1]. Nurses are exposed to experience the offensive behaviors at work than other employees [2]. Since the job brings the nurses physically and emotionally close to patients and other staff members, they are with the highest rate of sexual harassment in the profession [3]. One in forth nurse worldwide reported exposure to sexual harassment [2].

Even though upwards of $90 \%$ of nurses are female, nurses still experience sexual harassment from their coworkers and colleagues [4]. In addition to this, the other

(c) The Author(s). 2020, corrected publication 2020. Open Access This article is licensed under a Creative Commons Attribution 4.0 International License, which permits use, sharing, adaptation, distribution and reproduction in any medium or format, as long as you give appropriate credit to the original author(s) and the source, provide a link to the Creative Commons licence, and indicate if changes were made. The images or other third party material in this article are included in the article's Creative Commons licence, unless indicated otherwise in a credit line to the material. If material is not included in the article's Creative Commons licence and your intended use is not permitted by statutory regulation or exceeds the permitted use, you will need to obtain permission directly from the copyright holder. To view a copy of this licence, visit http://creativecommons.org/ licenses/by/4.0/. The Creative Commons Public Domain Dedication waiver (http://creativecommons.org/publicdomain/zero/1. 0/) applies to the data made available in this article, unless otherwise stated in a credit line to the data. 
sources of sexual harassment are patients, patients' families, and visitors who account for some harassment $[1,5]$. A report showed that female nurses were more sexually harassed by patients than male nurses, $73 \%$ for female nurses and $46 \%$ for male nurses respectively [6]. The prevalence of sexual harassment by patients was also high, with $60 \%$ of female nurses worldwide reporting the incident $[2,7]$.

Research on sexual harassment in the workplace is in its infancy, but according to the European Union, 40$50 \%$ of women experienced sexual harassment or unwanted sexual behavior in their workplace [8]. The report on the global supply chain showed that $85 \%$ of female employees were concerned with sexual harassment [9]. In a field dominated by women, nurses are particularly susceptible to sexual harassment in the workplace [10]. In a study, $91 \%$ of nurses reported experiencing at least one type of sexual harassment, 30\% experienced more than three and about 5\% reported on five or more types of sexual harassment [11]. However the female nurses' aspect is little known.

Sexual harassment is an unwelcome and offensive conduct of a sexual nature that may make workers feel humiliated, intimidated or uncomfortable [9]. It is unwelcome sexual advances, requests for sexual favors, and other verbal or physical conduct of a sexual nature that is directed toward a person in the workplace [12].

Sexual harassment has also taken many forms [9]. It may include unwelcome verbal, visual, nonverbal, or physical conduct that is of a sexual nature or based on someone's sex [13]. The Physical form of harassment is unwelcome touching, fondling, hugging or kissing. Verbal form of harassment includes sexually suggestive, offensive, comments or jokes; inappropriate invitations to go out on dates; intrusive, offensive questions about private life; intrusive, offensive comments about a woman's physical appearance. Non-verbal forms is inappropriate, intimidating, staring or leering; receiving or being showed offensive, sexually explicit pictures, photos or gifts; indecent exposure; being made to watch or look at pornographic material against one's wishes. The last is the use of technological cyber harassment faced by receiving unwanted, offensive, sexually explicit emails or SMS messages; inappropriate, offensive advances on an internet website or in an internet chat room [9].

In the sexual harassment, a perpetrator is a harasser who may be a woman or a man [14]. Therefore, the perpetrator of sexual harassment in this study would be any of the male or female gender around the female nurses' working area. According to the World Health Organization (WHO), the perpetrators of harassment and violence may be persons in positions of authority who are respected and trusted such as physicians [10]. Data also showed that sexual harassment is a demonstration of personal power over others [15]. A qualitative study showed that physicians were at the top of hierarchy as perpetrators and the nurses at middle level of hierarchy [3]. In addition to this, the prevalence of sexual harassment committed on nurses was $82 \%$ by physicians, $20 \%$ by coworkers and $7 \%$ by immediate supervisors were accounted for most incidents [5]. In another online survey, $5 \%$ out of 749 female nurses had experienced sexual harassment by another staff member including physicians in past 3 years of the study [16].

Sexual harassment can affect individuals in a number of ways, including their mental and physical health, finances, and opportunities to advance in their careers [13]; victims of sexual harassment can suffer significant psychological effects, including anxiety, depression, headaches, sleep disorders, weight loss or gain, nausea, lowered self-esteem and sexual dysfunction [17]. Any of those would be considered as the health consequences of sexual harassment in this review.

Though increasingly sexual harassment and violence are considered as important occupational safety and health issues, it is largely invisible and unreported [9]. This is especially true considering that many nurses fail to report incidents of harassment, no matter who was at fault. Many nurses have developed a thick skin, and are used to the "sexy nurse" stereotypes that doctors, patients and other nurses may impose on them. The reasons for non-reporting sexual harassment are complex and multifaceted but typically include fear of retribution or ridicule, and a lack of confidence in investigators, police and on other health workers [10]. In addition to this, many hospitals overlook harassment done by their most accomplished physicians, even reported $[4,5]$. The sexual harassment by co-workers as well as patients were also an issue that has received considerably less attention than physical and nonphysical violence [2].

There is an abundance of research papers and qualitative reviews on sexual harassment against nurses in general, to our knowledge there are no quantitative reviews specifically on female nurses. Most studies and reviews were focused on non-nurse women [18]. Studies among nurses were with a mix of male and female nurse participants and student nurses [2]. It is of great importance to examine the prevalence, types of sexual harassment, perpetrators, and health consequences of sexual harassment to female nurses. On the part of the victim, it may help in understanding sexual harassment more clearly and inform policymakers, get priority attention and for its protective measures. Female nurses are a graduated nurse assigned to provide care for healthy or ill clients. Prevalence is the percentage of female nurses that faced sexual harassment.

\section{Objectives}

This systematic review was to determine the prevalence of sexual harassment against the female nurses, types of 
sexual harassment, perpetrators, and its health consequences on female nurses working in hospitals reviewing observational studies.

\section{Research questions}

What is the prevalence of sexual harassment against female nurses, what are the types of sexual harassment, who are the perpetrators, what is the health consequence of sexual harassment on female nurses from observational studies?

\section{Method}

\section{Review protocol}

The Preferred Reporting Items for Systematic Reviews and Meta-Analysis 2009 (PRISMA 2009) guideline was followed to report in this systematic review [19]. Electronic searches were completed on 30 August, 2018 of the complete databases Scopus (from 2004), Google Scholar (from Nov. 2004), Pubmed (from June 1997), Web of Science (from 1997) and ProQuest (from1972). This extended time and suitable database use were to get adequate information.

All studies globally conducted on sexual harassment against female nurses were searched and used in the analysis. The systematic search was from suitable databases to identify potentially eligible articles for the analysis. To screen eligible articles, inclusion criteria were set. A retrieve of statistics from the articles was done and descriptive analyses were conducted. Analyses began by computing the weighted mean to pool the percentage or proportions of female nurses' exposure to sexual harassment with respect to prevalence, types of sexual harassment, perpetrators and health consequences of sexual harassment on female nurses from the articles.

\section{Eligibility criteria}

We searched for studies on sexual harassment. The eligible articles included in the review study were: Observational studies on female nurse participants, full text, published in peer-reviewed English journals, concerning prevalence of sexual harassment, and on female nurses who were graduated and working in any health facility to provide care for well or ill clients. But qualitative studies, reviews, and abstracts were excluded. Since the outcome is sexual harassment against female nurses, studies among male gender or any mix of male and female nurses as participants were excluded. Student nurses and other women in non-nursing employment were also excluded.

\section{Information sources}

The comprehensive literature search was focused on sexual harassment against female nurses. Studies were identified by searching out the following electronic databases: PubMed, Scopus, ProQuest, and Web of Science and Google Scholar. All searches were limited to the English language in scholarly journals and full text articles.

\section{Search strategy}

The Electronic searches were done to get potentially eligible studies. The following key terms were used in each database. From the advanced Google Scholar search was "sexual harassment OR sexual OR violence OR sexual OR assault "female nurses" limited to words occur anywhere in the article. The advanced search on Pubmed was "(((([sexual) AND [violence]) OR [harassment]) OR [assault])" limited to full free articles and studies on females. The search on ProQuest was "ti (sexual harassment) OR ti (sexual violence), ti (sexual assault) AND ti (female nurses)". On Scopus was "sexual AND harassment AND violence OR assault AND female AND nurse". On Web of Science "TI= (sexual AND harassment)" OR "TI=(sexual AND violence)" OR "TI=(sexual AND assault)" AND "TI=(female AND nurses)" and combination of terms was used.

\section{Study selection}

The search identified a total of 9346 records. During the initial screening, 103 duplicate records were removed. Out of the 9243 records, 9054 records was excluded based on the title and the abstract. Afterwards, full-text articles $(n=189)$ were independently reviewed if they met the inclusion criteria for this systematic review by two reviewers. Out of the 189 articles, excluded articles were: 99 articles on other forms of violence, 27 articles qualitative and review in design, 31 were with gender mix and student nurse in participants, 12 dealt on other health care providers and other women employee participants. Finally, a total of 20 articles was found eligible for this systematic review. The PRISMA flow chart was used in the selection as shown in Fig. 1 [19]. Discrepancies in article selection of the two reviewers were resolved by discussion. For issues with disagreement, resolved by a third reviewer.

\section{Data collection process and data items}

Before the synthesis of the primary studies, the documents were read thoroughly to gain an initial sense of the data by two authors. The two authors independently identified items with their percentages and recorded in a tabulated data sheet. The data sheet includes authors' name and year of publication, study country, study design, the sample size of female nurses, items for type sexual harassment with their forms, perpetrator list with its percentage and items of health consequences of sexual harassment with their forms were identified. The first and second authors independently examined the 


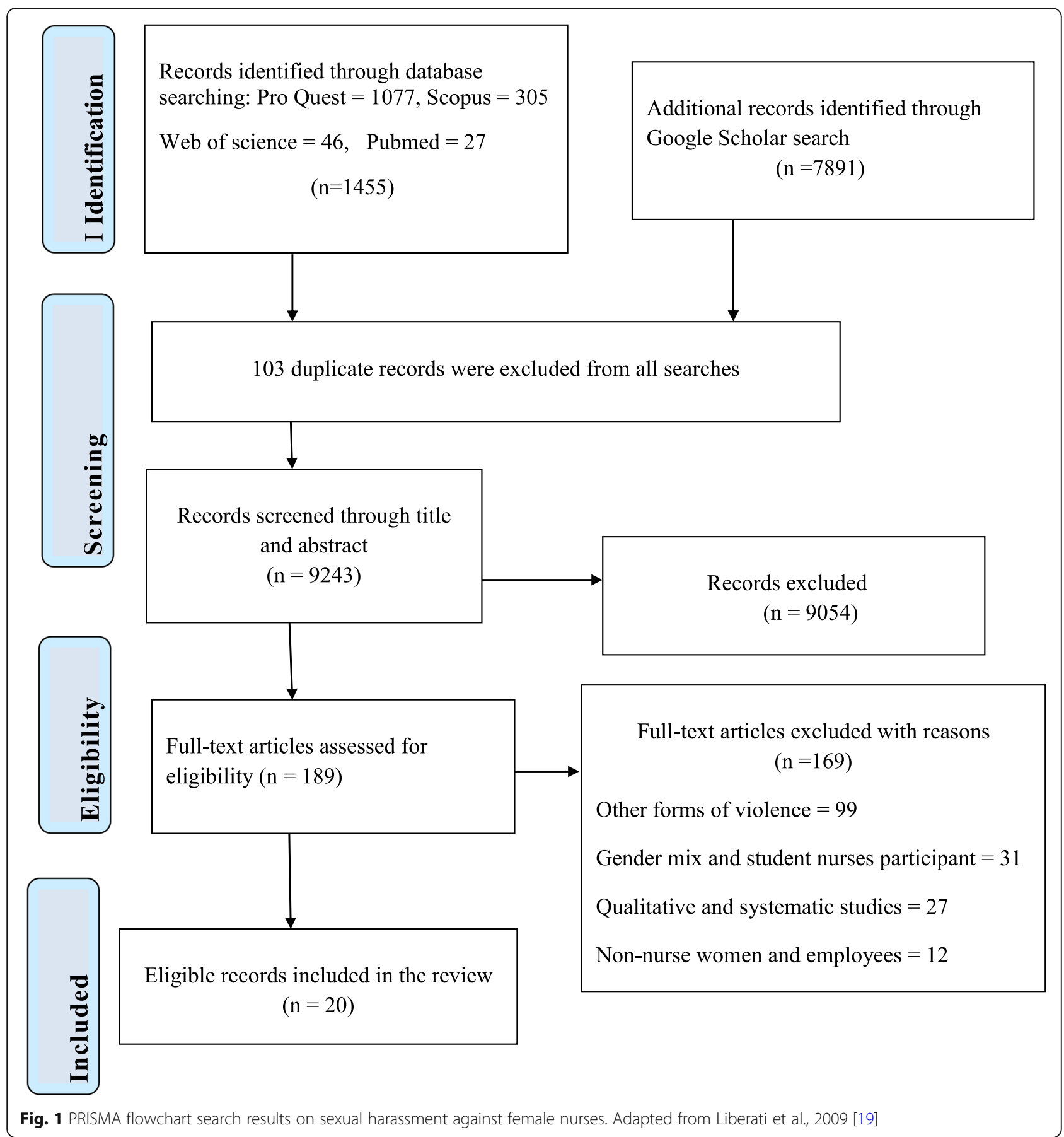

included studies and the first author extracted the relevant data, which was cross-checked by the second author. For issues with disagreement, resolved by a third reviewer.

\section{Risk of bias in each study}

The two reviewers independently reviewed each article of its quality. The quality of the articles was evaluated using the Modified Newcastle Ottawa Scale for Crosssectional Studies Quality Assessment Tool before the analysis. The tool has ordinal scoring for the following components: the representativeness of the samples, sample size, non-response rate, and use of a validated tool, comparability, outcome and statistical test. Each component is rated as $9-10$ points of very good study, 7-8 points for good studies, 5-6 points for satisfactory studies and 0 to 4 points for unsatisfactory studies in quality [20]. These articles, which scored satisfactory or more ( $\geq 5$ scores) in quality were included in this systematic review. The two reviewers scored a rating for 
each article. A third reviewer was involved solving the disagreement between the two reviewers in the rating of study quality. A final agreed-upon rating was assigned to each study (Table 1).

\section{Synthesis of results}

A descriptive analysis was done to get weighted mean of the percentages or proportions of the prevalence, perpetrators, each type of sexual harassment and health consequence items. Prevalence rates for studies were calculated as weighted means. The prevalence rate per study was multiplied by the corresponding sample size and divided by the total sample size of all studies. The results were summarized using descriptive statistics for this systematic review.

Types of sexual harassment and the consequences of sexual harassment were grouped into categories. The percentages and proportions of the items were pooled.

\section{Results}

\section{Study characteristics}

The studies included in this systematic review were 20 [21-40]. All of them were conducted on sexual harassment against female nurses in descriptive cross-sectional designs. The countries for the studies conducted in were: Four studies (20\%) in Pakistan, two (10\%) in Turkey, three (15\%) in Japan, two (10\%) in the United States, two (10\%) in Egypt. And these seven countries contributed one study (5\%) each: Malaysia, Nepal, Taiwan, Iceland, Kenya, Bangladesh, and South Korea. The total participants were 6600 (Table 1). All the studies reported the prevalence of sexual harassment and the types of sexual harassment or their forms. Fifteen (75\%) studies reported at least one or more perpetrators. For the consequences of sexual harassment, fifteen $(75 \%)$ studies reported one or more symptoms or health consequences of sexual harassment to female nurses (Table 2).

\section{Prevalence of sexual harassment}

The prevalence of sexual harassment against female nurses ranged from $10 \%$ [33] to $87.30 \%$ [23]. The pooled prevalence was $43.15 \%$. The types of sexual harassment were verbal, non-verbal, psychological and physical in a sexual nature.

The 35\% of the female nurses (ranged 21.1 to $46.6 \%$ ) faced with verbal sexual harassment [23, 29, 30, 37]. Among the forms of verbal sexual harassment, $42.33 \%$ of participants (ranged 3.03 to $58.60 \%$ ) heard bad words with sexual matters $[23,24,28]$, and $25.45 \%$ (ranged 3.3 to $72 \%$ ) heard bad jokes on sexual matters [23, 28, 31, $32,34-36,38-40]$, and $37.8 \%$ of participants (ranged 13.58 to $57.3 \%$ ) faced with sexual comments or remarks $[23,24,36,40]$. Again, in the verbal form of harassment, $21.33 \%$ of participants (ranged 3.23 to $53 \%$ ) were being asked for prospective partner relationship [31, 35, 38]. The $8.45 \%$ of female nurses were being asked their private matters ranged 3.39 to 35.87 [34]. The $5.9 \%$ of the participants (ranged 5.35 to $6.11 \%$ ) were being asked for sexual relation unwillingly $[32,36]$. About $7.82 \%$ were invited a topic on sexual relations for discussion [36]. In addition to this, $10.34 \%$ of participants received unwanted mail/blackmail or telephone calls for sexual relation the rate ranged from 5.14 to $36 \%$ [23, 28, 32, 35, 36, 38].

One-third (32.6\%) of the female nurses was harassed in non-verbal type of visual sexual harassment [29]. In the forms of visual sexual harassment, $18.06 \%$ of female nurses (ranged 4.74 to $36.7 \%$ ) were harassed in a sexual suggestive look [31, 34-36]. About $38.17 \%$ were faced in an unwanted sexual attention [23] and $57.67 \%$ of participants (ranged 14.95 to $70.9 \%$ ) were in the form of staring at nurses' body [24, 28]. The $19.89 \%$ (ranged 2.7 to $65 \%$ ) were harassed in facial expression forms [23, 32, $35,38]$. The perpetrators removed their clothes and showed their body's sexuality or naked picture $9.8 \%$, it ranged 2.24 to $40 \%$ [23, 28, 32, 35, 36, 38].

In respect of the physical sexual harassment type, 31\% of participants (ranged 11.64 to 59.7\%) were harassed physically [29-31, 37]. The $13.68 \%$ of participants $(4.48$ to $24.28 \%$ ) tried to be touched their body by perpetrators [28, 34, 36], and $11.04 \%$ of nurses' body unnecessarily and without their permission were touch (ranged 4.22 to $41.67 \%)[23,24,28,31,32,34,35,38-40]$. The $8.23 \%$ of participants requested to touch patient's body [31]. To $0.65 \%$ of the participants, patients tried to bring the nurses to their bed [34]. The $1.24 \%$ of the participants (ranged 0.9 to $2.24 \%$ ) were raped [24, 28, 31] and the $1.71 \%$ were faced sexual assault, the rate ranged 0.16 to $3.56 \%[30,32,34]$.

The $40.8 \%$ of the female nurses were faced with psychological type of sexual harassment in one study [29]. About 5.28\% were threatened for sex, ranged 2.16 to $9.6 \%$ [24, 28, 34]. The $30.55 \%$ were pressured for an intercourse [24]. About $41.4 \%$ got unwanted sexual attention and $46.1 \%$ were exposed to unwanted seductive behavior [39]. About 3.3\% were exposed to gossip [36], and the $7.72 \%$ in stalking form of harassment, the rate ranged 1.08 to $9.8 \%$ [23, 31, 34], $11.2 \%$ were exposed to whistling behavior [23], and $15.17 \%$ were for forced identification [23] (Table 1).

\section{Perpetrators of the sexual harassment against the female nurses}

The perpetrators of sexual harassment against female nurses were patients, patients' families or visitors, physicians, nurses, and other coworkers. The $46.59 \%$ of the participants (ranged 2.8 to $94 \%$ ) were harassed by patients in 12 studies [23, 24, 26-28, 32, 34, 35, 37-41]. About $27.74 \%$ of participants harassed (ranged 5.4 to 
Table 1 Prevalence, types and forms of sexual harassment against female nurses

\begin{tabular}{|c|c|c|c|c|c|}
\hline Authors and Year & Country & Sample size & Prevalence & Types and forms of sexual harassment & $\begin{array}{l}\text { Quality Score } \\
(0-9)\end{array}$ \\
\hline Othman et al. 2018, [21] & Kenya & 120 & $27.50 \%$ & Sexual harassment & 5 \\
\hline Fatema 2017, [22] & Bangladesh & 133 & $71.00 \%$ & Sexual harassment & 5 \\
\hline Hussein et al.2015, [23] & Egypt & 110 & $87.30 \%$ & $\begin{array}{l}\text { Verbal forms: Verbal comments to } 27.57 \% \text {, Talking sexual } \\
\text { words to } 3.03 \% \text {, Saying sexual jokes to } 3.3 \% \text {, Sending } \\
\text { telephone to } 12.43 \% \\
\text { Non-verbal: Whistling to } 11.2 \% \text {, sex look to } 38.17 \% \text {, Waving } \\
\text { to } 5.13 \% \text {, Forced identification to } 15.17 \% \text {, Stalking to } 2.7 \% \text {, } \\
\text { Touching nurses' body to } 4.23 \% \text {, Removal of clothes to } 2.70 \%\end{array}$ & 7 \\
\hline Ali et al.2015, [24] & Egypt & 430 & $70.20 \%$ & $\begin{array}{l}\text { Staring in suggestive manner at } 70.90 \% \text { of female nurses, } \\
\text { Talking by sexual words to } 58.60 \% \text {, Comments or jokes to } \\
57.30 \% \text {, Unnecessary touches to } 49.30 \% \text {, Making an intercourse } \\
\text { offer to } 30.5 \% \text {,Threatened sex to } 9.6 \% \text {, Rape to } 1.30 \%\end{array}$ & 7 \\
\hline Mushtaq et al. 2015, [25] & Pakistan & 200 & $71.66 \%$ & Sexual harassment & 6 \\
\hline Khan et al.2015, [26] & Pakistan & 150 & $80 \%$ & Sexual harassment & 5 \\
\hline Park et al. 2015, [27] & South Korea. & 970 & $19.70 \%$ & Sexual harassment & 6 \\
\hline Subedi et al.2013, [28] & Nepal & 134 & $40.30 \%$ & $\begin{array}{l}\text { Verbal: Vulgar words heard by } 22.39 \% \text {, Vulgar jokes heard } \\
\text { by } 35.82 \% \text {, } \\
\text { Visual: People staring at } 14.93 \% \text { nurses' body } \\
\text { People showing naked pictures to } 2.24 \% \\
\text { Contact: Trying to touch } 4.48 \% \text { of nurses } \\
\text { Embracing without permission to } 18 \% \\
\text { Blackmail for sex to } 2.24 \% \text {, } \\
\text { Threatening for sex to } 2.24 \% \\
\text { Facing rape like situation to } 2.24 \%\end{array}$ & 5 \\
\hline $\begin{array}{l}\text { Suhaila \& Rampal } \\
\text { 2012, [29] }\end{array}$ & Malaysia & 455 & $51.20 \%$ & $\begin{array}{l}\text { Verbal sexual harassment to } 46.60 \% \text {, Visual harassment to } 24.80 \% \\
\text { Psychological harassment to } 20.90 \% \text {, Physical harassment to } 20.70 \% \\
\text { Non-verbal harassment to } 16.70 \%\end{array}$ & 6 \\
\hline Shiao et al. 2010, [30] & Taiwan & 842 & $28.10 \%$ & Sexual harassment, Physical Harassment,Verbal Harassment Assault 3.5\% & 7 \\
\hline Hibino et al. 2009, [31] & Japan & 464 & $56 \%$ & $\begin{array}{l}\text { Sexual jokes to } 64.30 \% \text { of the nurses, Physical contact to } 59.70 \% \text {, } \\
\text { Gazing with sexual interest to } 36.70 \% \text {, Request for dating to } 27.20 \% \text {, } \\
\text { Request to touch patients body to } 14.80 \% \text {, Hugging to } 14 \% \text {, Stalking } \\
\text { to } 9.80 \% \text {, Rape to } 0.90 \%\end{array}$ & 7 \\
\hline Celik \& Celik 2007, [32] & Turkey & 622 & $37.10 \%$ & $\begin{array}{l}\text { Sexual Harassment } \\
\text { Uninvited sexual jokes, stories, questions, or words to } 11.62 \% \\
\text { Allusive sexual behaviors with the eye, hand, or face to } 6.98 \% \\
\text { Unwillingly asked out to } 6.1 \% \text {, Unwanted mail or telephone calls } \\
\text { to } 5.14 \% \text {, Touched on the body to } 4.22 \% \text {, Perpetrators shown their } \\
\text { body sexually } \\
\text { to } 3.98 \% \text {, Any attempt to assault to } 0.18 \%\end{array}$ & 7 \\
\hline $\begin{array}{l}\text { Gunnarsdottir et al. } \\
\text { 2006, [33] }\end{array}$ & Iceland & 600 & $10 \%$ & Sexual harassment to $10 \%$ & 8 \\
\hline Hibino et al. 2006, [34] & Japan & 464 & $55.80 \%$ & $\begin{array}{l}\text { Verbal: Making sexual jokes and remarks to } 12.28 \% \text {, Asking about } \\
\text { private matters to } 5.39 \% \text {, Asking for dating in } 3.23 \% \text {, Making threats } \\
\text { to } 2.16 \% \\
\text { Non-verbal: Gazing at nurses to } 4.74 \% \\
\text { Stalking or visiting the nurse at her home to } 1.08 \% \\
\text { Contact: Touching the nurse's body to as hugging to } 10.78 \% \text {, Trying } \\
\text { to touch nurses' body in } 10.78 \% \text {, Requesting the nurse to touch the } \\
\text { patient's body, Trying to bring the nurse to the patient's bed, } \\
\text { Attempting to sexually assault the nurse to } 0.43 \%\end{array}$ & 8 \\
\hline Kisa et al. 2002, [35] & Turkey & 215 & $73 \%$ & $\begin{array}{l}\text { Suggestive looks to } 20 \% \text {, Sexual teasing and jokes to } 19 \% \text {, Suggestive } \\
\text { physical gestures to } 18 \% \text {, Pressure for dates to } 14 \% \text {, Unwanted letters, } \\
\text { telephone calls to } 10 \% \text {, Exposure of parts of the, body in a sexually } \\
\text { suggestive way to } 11 \% \text {, Brushing, touching or grabbing to } 19.53 \%\end{array}$ & 5 \\
\hline Matsuoka et al.2001, [36] & Japan & 243 & $49.4 \%$ & $\begin{array}{l}\text { Touching to } 5.35 \% \text {, gossip to } 3.3 \% \text {, brought up the topic of sexual } \\
\text { relations to } 7.82 \% \text { Asking sexual relations to } 5.35 \% \text {, touch body to } 5.35 \text {, } \\
\text { tried to touch nurses body in } 24.28 \% \text {, sexual jokes or words to } 17.28 \% \\
\text { comment on body to } 13.58 \% \text {, gazing in an unpleasant manner to } 6.17 \% \text {, } \\
\text { Send nude photo to } 2.47 \% \text {, send letter/phone call containing sexual } \\
\text { issue to } 3.29 \%\end{array}$ & 6 \\
\hline Shaikh 2000, [37] & Pakistan & 89 & $43.67 \%$ & $\begin{array}{l}\text { Verbal sexual harassment to } 21.10 \% \\
\text { Physical sexual harassment to } 16.90 \%\end{array}$ & 5 \\
\hline
\end{tabular}


Table 1 Prevalence, types and forms of sexual harassment against female nurses (Continued)

\begin{tabular}{|c|c|c|c|c|c|}
\hline Authors and Year & Country & Sample size & Prevalence & Types and forms of sexual harassment & $\begin{array}{l}\text { Quality Score } \\
(0-9)\end{array}$ \\
\hline $\begin{array}{l}\text { Kisa \& Dziegielewski } \\
\text { 1996, [38] }\end{array}$ & Turkey & 229 & $75 \%$ & $\begin{array}{l}\text { Sexual teasing and jokes to } 72 \% \text {, Suggestive physical gestures to } 65 \% \text {, } \\
\text { Pressure for dates to } 53 \% \text {, Unwanted letters, telephone calls to } 36 \% \text {, } \\
\text { Exposure of parts of the body in a sexually suggestive way to } 40 \% \text {, } \\
\text { Brushing, touching or grabbing and grossly inappropriate touching to } \\
26.64 \%\end{array}$ & 7 \\
\hline Dan et al.1995, [39] & United States & 52 & $80 \%$ & $\begin{array}{l}\text { Sexual harassment } \\
\text { Suggestive stories or offensive jokes to } 51.9 \% \text {, Unwelcome seductive } \\
\text { behavior to } 46.1 \% \text {, Unwanted sexual attention to } 41.4 \% \\
\text { Deliberately touched and made uncomfortably to } 41.67 \% \text { Unwanted } \\
\text { discussion of personal or sexual matters to } 35.87 \%\end{array}$ & 5 \\
\hline $\begin{array}{l}\text { Libbus \& Bowman } \\
\text { 1994, [40] }\end{array}$ & United States & 78 & $71.80 \%$ & $\begin{array}{l}\text { Sexual jokes to } 13.46 \% \text {, Sexual remarks to } 19.23 \% \text {, Touch (brushing, } \\
\text { patting, hugging) to } 14.7419 \%\end{array}$ & 5 \\
\hline
\end{tabular}

Note: The study designs were descriptive cross sectional in all articles

$73 \%$ ) by patients' family in 9 studies $[24,27,28,32,35$, 37-41]. About $41.12 \%$ harassed by physician perpetrators, the rate ranged from 12.9 to $88.5 \%$ in 11 studies $[23,24,26-28,32,35,37-40]$. The $20 \%$ were harassed by nurses, the rate ranged 2.6 to $83 \%$ in five studies [23, $26,27,32,40]$. About $17.8 \%$ of participants were by other coworkers and staff and ranged from 1.6 to $45.40 \%$ in eight studies [24, 26-28, 32, 35, 38].

\section{Health consequences of sexual harassment on female nurses}

The health consequences of sexual harassment identified with this review were mental, psychological, emotional, physical and social health consequences. The $42.8 \%$ of female nurses developed mental health problem [32]. Anxiety was one of the mental problems with a mean score of 41.27 points [23]. The $16.76 \%$ of the victims (4.02 to $47.67 \%$ ) had depression [24, 29, 32, 35, 38] with the mean score level of 33.4 in its severity [23, 25].

Nearly one-third (30.19\%) of the female nurses had physical health problem due to sexual harassment, the rated ranged 8 to $37.14 \%$ [26, 32, 39]. Regarding symptoms of the physical consequences, $27.8 \%$ had a headache, the rate ranged from 14.95 to $57.5 \%$ [21, 32, 35, 38], $10.2 \%$ felt exhaustion, the rate ranged from 0.66 to $56.67 \%[21,29,32,35,38]$ and the $1.56 \%$ had dizziness ranged between 0.87 and $2.33 \%$ [35, 38].

The gastrointestinal tract related consequences were $10.79 \%$ of nurses lost their appetite, the rate ranged between 4.4 and $35 \%$ [21, 29]. About $13.33 \%$ had increased their appetite [21]. Nearly $4 \%$ female nurses had nausea or vomiting, the rate ranged between 2.79 and $4 \%$ [29, $35,38]$. The $13.51 \%$ diseased with gastritis, the rate ranged between 12.9 and $14 \%[35,38]$, and $11.59 \%$ of participants had stomach ache, the rate ranged between 6.43 and $38.34 \%[21,32]$. The $14.17 \%$ of nurses had weight gain and on the other hand $29.6 \%$ had weight loss [21].
Moreover, 48.33\% had nightmares [21], about $17.79 \%$ had sleep difficulty, the rate ranged between 9 and $54.17 \%$ of female nurses [21, 32, 35, 38]. The $7.22 \%$ of participants (ranged 0.87 to $20 \%$ ) had slept long $[21,35,38]$. The $8.51 \%$ of nurses had menstrual disturbances, the rate ranged between 2.33 and $27.5 \%$ [21, 35, 38]. Nearly $16 \%$ felt muscular pain or convulsed as physical health consequences [21].

More than half $(61.26 \%)$ of the female nurses were emotionally disturbed by sexual harassment, the rate ranged from $47.4 \%$ [39] to $70.5 \%$ [40] in two studies. In the emotional consequences, $29.51 \%$ became anger and nervous, the rate ranged 16.67 to $50.22 \%$ [24, 35, 38, 40]. About $21.56 \%$ felt fear and ferociousness, the rate ranged 8.68 to $41.1 \%$ in the seven studies [22, 24, 29, 32, 35, 38, 40]. The $16.84 \%$ of female nurses (ranged 53.72 to $54 \%$ ) were disappointed or felt sad [22, 24]. The $16.36 \%$ of the participants cried without reasons (35\%) ranged 10.6 to $35 \%[22,24]$ and $48 \%$ of the nurses felt sense of bitterness [22]. About 20.28\% of participants (ranged 14.10 to $21.40 \%)$ felt shame and embarrassment feelings [24, 40]. Nearly $9 \%$ of the participants (ranged 4.02 to $15.72 \%$ ) had feelings of belittlement and humiliation [32, 35, 38].

More than half $(51.79 \%)$ of nurses (ranged 38.24 to $66.53 \%)$ were psychologically disturbed as in three studies $[24,26,29]$. In the psychological suffer, 9.91\% felt guilt or self-blame, the rate ranged from $8.84 \%$ [35] to $10.92 \%$ [38]. The $19.6 \%$ had disgust [40], 25\% lost their self-confidence [22] and the $7.41 \%$ felt helplessness, the rate ranged $6.11 \%$ [38] to $11.63 \%$ [35].

There were also social health consequences to the female nurses due to the sexual harassment. The $16.02 \%$ of nurses had social disturbance, the rate ranged 13.67 to $27 \%$ [22, 32]. Again, $17.33 \%$ of the nurses had family life disturbance ranged 10.13 to $51 \%[22,32]$, and social isolation in $22 \%$ of participants [22] (Table 2).

\section{Discussion}

The result of this systematic yield $43.15 \%$ of female nurses sexually harassed and it ranged from 10 to $83.5 \%$ 
Table 2 Perpetrators and health consequences of sexual harassment on female nurses

\begin{tabular}{lll}
\hline Author/Year & Perpetrators & Consequences of sexual harassment \\
\hline Othman et al., $2018[21]$ & - & Headache on $57.5 \%$, fatigue on $56.67 \%$, difficult sleep on $54.17 \%$, \\
& Nightmare on $48.33 \%$, and loss of appetite on $35 \%$ of nurses \\
& $\begin{array}{l}\text { Stomach pain, weight gain, weight loss, disturbances of the } \\
\text { menstrual cycle, muscular spasm or convulsions, and gastric ulcer } \\
\text { disease or hypertensive. }\end{array}$
\end{tabular}

Fatema, 2017 [22]

Hussein et al., 2015 [23]

Ali et al., 2015 [24]

Mushtaq et al. 2015

Khan et al.,2015 [25]

Park et al., 2015 [27]

Subedi et al., 2013 [28]

Suhaila \& Rampal, 2012 [29]

Shiao et al., 2010 [30]

Hibino et al., 2009 [31, 34]

Celik \& Celik 2007 [32]

Gunnarsdottir et al., 2006 [33]

Hibino et al., 2006 [31, 34]

Kisa et al., 2002 [35]

Matsuoka et al., 2001 [36]

Shaikh, 2000 [37]
43.30\% patient /family 30\% follow nurse $26.70 \%$ doctors

42.70\% patients

$61.90 \%$ patients' family

$12.90 \%$ doctors

$45.40 \%$ staff

$-$

55.3\% patients/visitors

25.3\% physicians

4.7\% colleague nurses

$14.7 \%$ administration

$55.5 \%$ patients

$15.2 \%$ patient family

$34.6 \%$ physicians

$2.6 \%$ colleague nurses

$1.6 \%$ nurse managers

$18.52 \%$ patients

25.93\% patient relatives

37.03\% physician

$11.11 \%$ administrative staff

Patients

Patients' relatives

Colleagues

Medical Officers

Psychiatry patients

Patients

43.30\% patients $34.20 \%$ attendants

$77.10 \%$ physicians

$51.10 \%$ nurses

29.4\% other personnel

94\% male patients

$39 \%$ patients

$17 \%$ relatives of patient

$41 \%$ physicians

$4 \%$ other hospital staffs

$2.80 \%$ male patients

$11.27 \%$ male attendants

26.90\% male physicians
Feeling of sadness on $54 \%$, loss of self-confidence on $25 \%$, crying for no reason on $35 \%$ and

Social isolation on $22 \%$. Uncontrolled ferociousness on $19 \%$, trouble in emotional relationships on $27 \%$, and bitterness on $48 \%$.

Anxiety (Mean 41.27 \pm 6.12 ) $z=3.85, p=0.000$

Depression (Mean $33.40 \pm 4.44) \mathrm{z}=2.10, p=0.036$

Felt anger on $37.10 \%$

Felt shame on $30.40 \%$

Psychological in general on $94.7 \%$

Disappointment on $76.50 \%$

Depression on $67.90 \%$, and fear on $35.80 \%$

Depression, anxiety, stress

Psychological in general on $50.7 \%$

Physical health in general on $8 \%$

Psychological effects in general on74.70\%.

Fear on $80.30 \%$, depression on $26.6 \%$, loss of appetite on $8.60 \%$, nausea on $7.70 \%$, and fatigue on $1.30 \%$.

Night shift had negative effects on the score of general health (Coef-6, $\mathrm{SE}=2.7 \mathrm{p}=0.03$

Working in a psychiatric hospital was positively associated with scores in mental health (Coef 2.7,SE $=0.6 p<0.0001$ )

Working in psychiatry hospital was vitality, was negatively associated with these scores (Coef 1.7,SE $=0.7 p<0.0110$ )

Disturbed mental health on $44.6 \%$

Physical problem in general on $24.20 \%$

Sleeping difficulty on $24.20 \%$, headache on $40.30 \%$, stomach ache on $17.30 \%$, negative social and family relations on $36.80 \%$, disturbed family life on $27.30 \%$, being tired on $14.30 \%$, fear on $23.4 \%$, helplessness on $17.30 \%$, depression on $10.80 \%$, belittlement or humiliation on $10.8 \%$.

Psychological wellbeing affected

Emotional reactions -Anger on $42.9 \%$, fear on $11.4 \%$, helpless on $8.2 \%$, depression on $6.9 \%$, feelings of humiliation on $10.5 \%$, guilt/self-blame on $6.2 \%$.

Physical symptoms: Headaches on $37.7 \%$, Dizziness on $2 \%$, gastritis on $12.9 \%$, nausea and/or vomiting on $2.4 \%$, exhaustion on $12.9 \%$, menstrual disturbances on $2 \%$, inability to sleep on $20.2 \%$ and sleep more on $3.2 \%$.

Mental problem on $41 \%$ 
Table 2 Perpetrators and health consequences of sexual harassment on female nurses (Continued)

\begin{tabular}{|c|c|c|}
\hline Author/Year & Perpetrators & Consequences of sexual harassment \\
\hline Kisa \& Dziegielewski,1996 & $\begin{array}{l}34 \% \text { patients } \\
14 \% \text { relatives of patients } \\
44 \% \text { physicians } \\
9 \% \text { other perpetrators }\end{array}$ & $\begin{array}{l}\text { Emotional effects -Anger on } 44 \% \text {, feelings of humiliation on } 14 \% \text {, fear } \\
\text { on } 12 \% \text {, guilt on } 9 \% \text {, and depression on } 5 \% \text { and helplessness on } 5 \% \text {. } \\
\text { physical symptoms: Headaches on } 38 \% \text {, inability to sleep on } 20 \% \text {, } \\
\text { feelings of exhaustion on } 15 \% \text {,gastritis on } 14 \% \text {, nausea and/or vomiting } \\
\text { on } 4 \% \text {, tendency to sleep more than usual on } 1 \% \text {, dizziness on } 1 \% \text {, and } \\
\text { menstrual disturbances on } 1 \% \text {. }\end{array}$ \\
\hline Dan et al.,1995 [38] & $\begin{array}{l}75 \% \text { patients } \\
73 \% \text { visitors } \\
88.5 \% \text { physicians } \\
83 \% \text { coworkers }\end{array}$ & $\begin{array}{l}\text { Emotional condition on } 47.4 \% \text {. } \\
\text { Physical condition on } 11.1 \% \text {. }\end{array}$ \\
\hline Libbus \& Bowman,1994 [40] & $\begin{array}{l}53.5 \% \text { patients } \\
5.4 \% \text { patients' family } \\
25 \% \text { physicians } \\
12.5 \% \text { non-nurse staff } \\
3.6 \% \text { nurses }\end{array}$ & $\begin{array}{l}\text { Emotional responses on } 70.5 \% \text { (Anger on } 23.6 \% \text { ), embarrassment on } \\
19.6 \% \text {, disgust on } 19.6 \% \text {, nervousness on } 18.20 \% \text {. }\end{array}$ \\
\hline
\end{tabular}

in prevalence. This high prevalence is similar with previous studies resulted in 16 to $76 \%$ of nurses sexually harassed [42], and $53.7 \%$ of female nurses that perceived being harassed [43], 60\% of nurses harassed [44], 63.6\% of nurses in another study [45], and 66\% of nurses and nurses students face the harassment [46]. However, it is lower than the $91 \%$ of nurses and nurse students sexual harassed in medical centers [11]. This difference could be due to the mix in male and female nurse participants who had different roles of nurses and nurse students.

The study also indicated that female nurses were faced with multiple types harassments related to their sexual nature verbal, non-verbal, physical and psychological types of sexual harassment in their workplace. This result agrees with the types of sexual harassment experienced in health care workers [47].

The verbal type of sexual harassment happed to female nurses in different forms. Many of the female nurses heard bad words of sexual matters, bad jokes related sexual issues and the perpetrators were forwarding comments in a sexually manner. This shows similarity with other studies among nurses, nurse students and female graduates out nursing that faced verbal forms of sexual harassment [5, 11, 45, 48, 49]. The comment form of verbal harassment was lower in magnitude than the comments against nurses and student nurses [11]. This difference could be due to differences in study participants. In addition to this, the female nurses were harassed verbally as in unwanted mail/blackmail or telephone calls for sexual relations, asked their private matters, asked for a sexual relationship unwillingly, initiated for unnecessary sexual relations and were being asked for prospective partner relationship. There is similarity in these forms and magnitude with those female graduates got sexual messages posted on notice board, other got text messages for relation, asked to do something sexual in exchange for favors $[5,49]$. But the magnitude is lower than the study among nurses and student nurses that faced romantic relation [11]. This difference could be due to difference in participants of being male and female nurses and nurse students.

The study also indicated that non-verbal types of sexual harassment experienced in a significant number of female nurses. In a visual form, the female nurses had faced a suggestive sexual look or gazing at sexual interest and had been forced to see body sexuality or a naked picture of perpetrators. These forms are in keeping with nurses and nurse students faced leering or ogling and as in perpetrators showed or left sexual pictures to female graduate students $[46,49,50]$. This is significantly high harassment which could interfere with the nurses' day to day duties.

According to this review, a number of female nurses were also physically harassed. The physical type of the sexual harassments were in different forms. The female nurses' body was tried to be touched by perpetrators and the female nurses' body unnecessary and without their permission was also touched. It is consistent with other studies results as unnecessary and unwanted touches to nurses and other female graduates, intimated touching of nurses' body, unnecessary touching, patting, or pinching of body parts of nursing students, and female graduates and nurses forced to kiss someone or to do something sexual other than kissing $[11,46,49,50]$. In addition to the touch type of harassment, female nurses were raped, forced attempt on intercourse, faced sexual assault, requested to touch the patient's body and patient perpetrators tried to bring female nurses to perpetrator's bed. It is in keeping with the rape to employees, forced attempt on intercourse against nurses, and student nurses faced a proposition to the intimate relationship $[11,44,51]$.

In this systematic review, we found that female nurses were affected by the psychological type of sexual harassment in their workplace. One form of the psychological sexual harassment was a sexual threat to the female nurses. The result agrees with the nurses pressured for 
sexual cooperation [5]. To provide compassionate nursing care, female nurses should get the right to humanistic, peaceful and care related relationship with people stay in hospitals and other medical centers.

This review identified a number of different perpetrators in the sexual harassment against the female nurses. The first most and highest in rank of harassment against the female nurses was from clients; the $46.59 \%$ of female nurses were harassed by patients. Its rank and its range for the rate is consistent with other similar study results by patient harassers to $72.8 \%$ of nurses [45], $62.9 \%$ nurses [48], to other result of $58 \%$ nurses [44], and to $18-38 \%$ nurses and nurses students harassed by patients $[11,46]$. The second most source of harassment was by physicians. The $41.12 \%$ of female nurses were harassed by physicians. The rank and its rate agree with the $10-$ $30 \%$ of nurses and nurse students harassed [11], and $57.9 \%$ of nurses in other study [45].

About $27.74 \%$ of participants were harassed by patients' family. This is different result compared with the $3 \%$ nurses harassed by visitors [46]. The difference could be due to the participant difference gender of participants and the study design. The $20 \%$ of female nurses were harassed by nurses. This result is consistent in rank and the rate of the range with the $15-22 \%$ nurses and nurse students [11] and 13\% of nurses harassed by nurse [44]. Most of the harassers are stayed in the female nurses' working place health facilities. Therefore, there should be system design in hospitals and other medical centers to bide the harassers in creating safe working environment for the female nurses.

The result of this review showed that sexual harassment against the female nurses resulted in mental, physical, emotional, psychological and social health consequences. The consequences generally agree with workplace aggression consequences such as fear, anxiety, disappointment, and being helplessness on nurses and nurse students [52]. Again, shows similarity with the study reported the consequences of sexual harassment among nurses of the mental and physical health consequences in their workplace [48].

Mental health problem was one of the consequences of sexual harassment resulted in the female nurses. It is keeping with the workplace violence consequence of nurses [51]. The review identified the forms mental health consequences as anxiety, depression and stress. This finding show an agreement with other studies reported anxiety, depression and stress after sexual harassment to nurses and nurse student and female graduate students [5, 27, 49, 52].

The review indicated that sexual harassment against the female nurses led them to have the physical health consequences. The consequence manifested in the form of headache, exhaustion and for gastrointestinal disturbances gastritis, nausea or vomiting, weight gain or weight loss, neuromuscular problems such as muscle pain or convulsion and dizziness. These multiple manifestations get similarity with other study among nurses and nurses students $[5,18,44,46,50]$, In addition to these manifestations, the female nurses had other physical manifestation sleeping difficulty, had inability to sleep, and others abnormally slept long. This is in keeping with nurses, nurse students and female graduates students sleep disturbances $[43,49,50]$. However, headache is higher in magnitude compared to other study result [46]. This difference could be the participants' gender mix and its study design in that study.

In this review study nearly half of the female nurses emotionally disturbed due to the sexual harassment against them. This result agrees with the health consequence happened to health care workers [47]. It also indicated that forms of emotional disturbances felt by female nurses were becoming anger and nervousness, fear or become ferocious, had feeling of disappointment or sadness, shamefulness or embarrassment and feeling of humiliation and belittlement. It shows agreement with the study on nurses, nurse students and health worker harassment health consequences [18, 44, 46-48, 50, 52, 53]. But the magnitude of feeling of shamefulness, embarrassment, humiliation and belittlement were low compared to study results among nurses and nurses students working in medical centers [11]. The difference could be the gender mix and mix in roles of participants in that study.

The systematic review indicated that a significant number of female nurses was psychologically affected in their health due to the sexual harassment. They lost their confidence, become helpless, disgusted, had suffered from self-blame. It shows agreement with a study on behavioral consequences of sexual harassment on nurses, nurses and nurse students and other employees $[11,18,46,47,52]$. These all consequences happening to the female nurses are unexpected and unaccepted additional burden of the professionals which demand counseling service to the victims.

\section{Limitations}

This literature review provides an overview of knowledge on sexual harassment against female nurses. However, this review covers the articles only published in English, the reviewed articles were cross-sectional design. Most of the rates were calculated from a few study results and participants were only female who may not be representative of the nurse population.

\section{Conclusion}

According to this review, the prevalence of sexual harassment against female nurses is high and persisting in magnitude in the nursing profession. The types of sexual 
harassment include physical, verbal, non-verbal and psychological with their different forms in a sexual nature. First ranked perpetrators are the service demanding clients. The second next perpetrators are physicians that were assigned to improve the quality of health. Next third perpetrators are patients' family. The fourth ranked perpetrators of sexual harassment are nurses. The rest were other coworkers. Female nurses are being affected mentally, physically, and emotionally, socially and their psychology due to the sexual harassment.

This is the time policymakers to develop guidelines on work ethics, legal accountability, team work and counseling programs to manage and reduce the consequences of sexual harassment among being affected female nurse. The nursing associations are recommended initiating female nurses' workplace safety policies and strategies in hospitals to minimize this tradition in the profession. Health managers are recommended to create a safe and secure working environment for female nurses which contributes in improving the quality nursing care. Female nurses to create unity which able them to identify, prevent, minimize the occurrence of harassment and manage each consequence at spot in their working hospitals. Nursing curriculums to include sexual harassment prevention strategies and improve life skills of female nurses in tackling sexual harassments. Researchers to find out technology for information, communication and reporting systems of sexual harassment. It is also recommended investigating the factors associated with sexual harassment against the female nurse and use predictive research designs.

\section{Abbreviations}

NICU: Neonatal Intensive Care Unit; PRISMA: Preferred Reporting Items for Systematic Reviews and Meta-Analysis; WHO: World Health Organization

\section{Acknowledgments}

We would like to acknowledge the Tehran University Medical Sciences International Campus for the provision of internet access and the librarians in the Tehran University Medical Sciences, School of Nursing and Midwifery for their help during the database search.

\section{Authors' contributions}

WGK: idea for the review, study selection, data extraction, interpretation of results, writing of the manuscript. RN: study selection, data extraction, interpretation of results, writing of the manuscript. NDN: idea for the review, data extraction, writing of the manuscript. $\mathrm{MH}$ : study selection, writing of the manuscript. All authors read and approved the final manuscript.

\section{Funding}

There was no source of funding for this systematic review study.

\section{Availability of data and materials}

The datasets used during the current study are available from the corresponding author on request.

Ethics approval and consent to participate

Not applicable to this study.

Consent for publication

Not applicable.

\section{Competing interests}

We do not have potential conflicts of interest with respect to the research, authorship, and publication of this article.

\section{Author details}

'Department of Community Health and Geriatric Nursing, School of Nursing and Midwifery, International Campus, Tehran University of Medical Sciences (IC-TUMS), Tehran, Iran. ${ }^{2}$ Department of Midwifery, College of Medicine and Health Sciences, Adigrat University, Adigrat, Tigray, Ethiopia. ${ }^{3}$ Nursing and Midwifery Care Research Center, School of Nursing and Midwifery, Tehran University of Medical Sciences, Nosrat St., Tohid Sq., Tehran Postal code: 1419733171, Iran. ${ }^{4}$ Department of Critical Care Nursing and Nursing Management, School of Nursing and Midwifery, Tehran University of Medical Sciences, Tehran, Iran. ${ }^{5}$ Department of Pediatrics Nursing and Neonatal Intensive Care, School of Nursing and Midwifery, Tehran University of Medical Sciences, Tehran, Iran.

Received: 15 May 2019 Accepted: 18 June 2020

Published online: 13 July 2020

\section{References}

1. NACNEP: Violence against nurses: an assessment of the causes and impacts of violence in nursing education and practice. Fifth annual report. In.; 2007.

2. Spector PE, Zhou ZE, Che XX. Nurse exposure to physical and nonphysical violence, bullying, and sexual harassment: a quantitative review. Int I Nurs Stud. 2014:51(1):72-84.

3. Lamesoo K. "Some things are just more permissible for men": Estonian Nurses' interpretations of sexual harassment. NORA-Nordic J Femin Gender Res. 2013;21(2):123-39.

4. Coyle MC, Sumida J: California's experiment in interactive sexual harassment prevention training: Will it reduce workplace harassment claims. Employee Relat Law J. 2005;31(2):3-16.

5. Valente SM, Bullough V. Sexual harassment of nurses in the workplace. Nurs Care Qual. 2004;19(3):234-41.

6. Frellick M: Harassment from patients prevalent, poll shows. Medscape 2018 report..

7. Tekin YE, Bulut H. Verbal, physical and sexual abuse status against operating room nurses in Turkey. Sex Disabil. 2014;32(1):85-97.

8. World Health Organization. Understanding and addressing violence against women: Sexual violence. World Health Organization; 2012.

9. Organization IL: Gender-based violence in global supply chains: Resource Kit In: Module 3: Global supply chains and gender-based violence in the world of work. 2018.

10. Organization WH: Guidelines for medico-legal care of victims of sexual violence. In. 2003.

11. Bronner G, Peretz C, Ehrenfeld M. Sexual harassment of nurses and nursing students. J Adv Nurs. 2003;42(6):637-44.

12. What is sexual harassment? [https://employment.findlaw.com/employmentdiscrimination/sexual-harassment-what-is-it.html.].

13. Shaw E, Hegewisch A, Hess C. Sexual harassment and assault at work: understanding the costs. Instit Women's Policy Res Publication. 2018;376.

14. Keyton J, Rhodes SC. Sexual harassment: A matter of individual ethics, legal definitions, or organizational policy? J Bus Ethics. 1997;16(2):129-46.

15. Janice Rider Ellis CLH: Nursing in today's world: Trends, issues, and management. In., 10 edn. Philadelphia: Wolters Kluwer Health | Lippincott Williams \& Wilkins; 2012.

16. Locke T: 'Truly shocking': Medscape UK nurses' sexual harassment survey results. Medscape 2019 report.

17. Kaplan SJ. Consequences of sexual harassment in the workplace. Affilia 1991;6(3):50-65.

18. Pina A, Gannon TA. An overview of the literature on antecedents, perceptions and behavioural consequences of sexual harassment. J Sex Aggress. 2012;18(2):209-32.

19. Liberati A, Altman DG, Tetzlaff J, Mulrow C, Gøtzsche PC, loannidis JP, Clarke M, Devereaux PJ, Kleijnen J, Moher D. The PRISMA statement for reporting systematic reviews and meta-analyses of studies that evaluate health care interventions: explanation and elaboration. PLoS Med. 2009; 6(7):e1000100.

20. Herzog R, Álvarez-Pasquin MJ, Díaz C, Del Barrio JL, Estrada JM, Gil Á. Are healthcare workers' intentions to vaccinate related to their knowledge, beliefs and attitudes? A systematic review. BMC Public Health. 2013;13(1):154. 
21. Othman BEM, Mahgoub NA, Abdo SE, Adel N. Effects of Sexual Harassment on Nurses Bio-Psychosocial Health at Cairo University Hospitals. Int J Innov Res Dev. 2018:7(4).

22. Fatema SR. Socio-psychological health hazards and job satisfaction among the female nurses in the selected public hospitals of Bangladesh. Int J Res Health Sci Nurs. 2017;3(9):01-9.

23. Hussein AA, Mabrouk SM, Abed GA. Workplace sexual harassment against female nurses and occupational health outcomes. J Nurs Health Sci. 2015; 4(3):66-77.

24. Ali EAA, Saied SM, Elsabagh HM, Zayed HA. Sexual harassment against nursing staff in Tanta University hospitals, Egypt. J The Egyptian Public Health Assoc. 2015;90(3):94-100.

25. Mushtaq M, Sultana S, Imtiaz I. The trauma of sexual harassment and its mental health consequences among nurses. J Coll Phys Surgeons Pak. 2015; 25(9):675-9.

26. Khan N, Begum S, Shaheen A. Sexual harassment against staff and student nurses in tertiary care hospitals Peshawar KP Pakistan. Int J Innov Res Dev. 2015;4(1).

27. Park M, Cho SH, Hong HJ. Prevalence and perpetrators of workplace violence by nursing unit and the relationship between violence and the perceived work environment. J Nurs Scholarsh. 2015;47(1):87-95.

28. Subedi S, Hamal M, Kaphle HP. Sexual harassment in the hospital: are nurses safe. Int J Health Sci Res. 2013;3(6):41-7.

29. Suhaila O, Rampal K. Prevalence of sexual harassment and its associated factors among registered nurses working in government hospitals in Melaka state, Malaysia. Med J Malaysia. 2012;67(5):506-17.

30. Shiao JS-C, Tseng Y, Hsieh Y-T, Hou J-Y, Cheng Y, Guo YL. Assaults against nurses of general and psychiatric hospitals in Taiwan. Int Arch Occup Environ Health. 2010;83(7):823-32.

31. Hibino $Y$, Hitomi $Y$, Kambayashi $Y$, Nakamura $H$. Exploring factors associated with the incidence of sexual harassment of hospital nurses by patients. J Nurs Scholarsh. 2009:41(2):124-31

32. Çelik Y, Çelik SŞ. Sexual harassment against nurses in Turkey. J Nurs Scholarsh. 2007:39(2):200-6.

33. Gunnarsdottir HK, Sveinsdottir H, Bernburg JG, Fridriksdottir H, Tomasson K. Lifestyle, harassment at work and self-assessed health of female flight attendants, nurses and teachers. Work. 2006;27(2):165-72.

34. Hibino $Y$, Ogino $K$, Inagaki M. Sexual harassment of female nurses by patients in Japan. J Nurs Scholarsh. 2006;38(4):400-5.

35. Kisa A, Dziegielewski SF, Ates M. Sexual harassment and its consequences: a study within Turkish hospitals. J Health Soc Policy. 2002;15(1):77-94.

36. Matsuoka K, Kurita H, Abe R, Osada H. Mental health of Japanese nurse victims of sexual harassment. Arch Women's Mental Health. 2001;4(1):1-4.

37. Shaikh MA. Sexual harassment in medical profession perspective from Pakistan. J Pak Med Assoc. 2000:50(4):130-1.

38. Kisa A, Dziegielewski SF. Sexual harassment of female nurses in a hospital in Turkey. Health Serv Manag Res. 1996;9(4):243-53.

39. Dan AJ, Pinsof DA, Riggs LL. Sexual harassment as an occupational hazard in nursing. Basic Appl Soc Psychol. 1995;17(4):563-80.

40. Libbus MK, Bowman KG. Sexual harassment of female registered nurses in hospitals. J Nurs Admin. 1994:24(6):26-31.

41. Jafree SR. Workplace violence against women nurses working in two public sector hospitals of Lahore, Pakistan. Nurs Outlook. 2017:65(4):420-7.

42. Rippon TJ. Aggression and violence in health care professions. J Adv Nurs. 2000:31(2):452-60

43. Fiedler A, Hamby E. Sexual harassment in the workplace: Nurses' perceptions. JONA. 2000;30(10):497-503.

44. Cogin J, Fish A. Sexual harassment-a touchy subject for nurses. J Health Organ Manag. 2009;23(4):442-62.

45. Williams MF. Violence and sexual harassment: impact on registered nurses in the workplace. AAOHN J. 1996:44(2):73-7.

46. Finnis SJ, Robbins I. Sexual harassment of nurses: an occupational hazard? J Clin Nurs. 1994;3(2):87-95.

47. Nielsen MBD, Kjær S, Aldrich PT, Madsen IE, Friborg MK, Rugulies R, Folker AP. Sexual harassment in care work-dilemmas and consequences: a qualitative investigation. Int J Nurs Stud. 2017:70:122-30.

48. Chang HE, Cho S-H. Workplace violence and job outcomes of newly licensed nurses. Asian Nurs Res. 2016:10(4):271-6.

49. Owoaje ET, Olusola-Taiwo O. Sexual harassment experiences of female graduates of Nigerian tertiary institutions. Int Quart Commun Health Educ. 2010;30(4):337-48
50. Cholewinski JT, Burge JM. Sexual harassment of nursing students. Image. 1990;22(2):106-10.

51. Nielsen MB, Bjørkelo B, Notelaers G, Einarsen S. Sexual harassment: prevalence, outcomes, and gender differences assessed by three different estimation methods. J Aggress Maltreat Trauma. 2010;19(3):252-74.

52. Magnavita N, Heponiemi T. Workplace violence against nursing students and nurses: an Italian experience. J Nurs Scholarsh. 2011;43(2):203-10.

53. Bruen J: Sexual harassment towards nurses in their working environment; patients as the perpetrators. 2017.

\section{Publisher's Note}

Springer Nature remains neutral with regard to jurisdictional claims in published maps and institutional affiliations.
Ready to submit your research? Choose BMC and benefit from:

- fast, convenient online submission

- thorough peer review by experienced researchers in your field

- rapid publication on acceptance

- support for research data, including large and complex data types

- gold Open Access which fosters wider collaboration and increased citations

- maximum visibility for your research: over $100 \mathrm{M}$ website views per year

At BMC, research is always in progress.

Learn more biomedcentral.com/submissions 